\title{
Towards the conceptualisation of flow in corporate financial reporting theory
}

\author{
AREHWINKEL ${ }^{1}$ AND DG GOUWS ${ }^{2}$
}

\author{
The flux of time is the reality itself, \\ and the things which we study are the \\ things which flow.
}

Henri Bergson (1911:363)

\begin{abstract}
Developments in science, technology and sophisticated interconnected social networks increase the speed and volatility of the flow of economic-related energies, such as financial and intellectual capital. These developments require an information theory on corporate financial reporting that is stable at a fundamental level and focused on the disclosure of those systemic attributes that are pivotal to the sustenance of business entities operating in the global economy, or in economies with similar traits. The limited success in attaining stability is caused by, among others, the application of diverse, restricted and even opposing perspectives, resulting in random theoretical development, often unaligned with economic reality. The main aim of the article is to investigate whether the introduction of an underlying concept, principle or theorem, founded on the phenomenon of flow, to generalpurpose corporate financial reporting theory could contribute to rendering stable guidance for coherent theoretical development while simultaneously enhancing alignment with the current global economy. As the study was conducted at conceptual level, a qualitative, transdisciplinary theoretical research methodology was applied by taking into account related basic concepts of philosophy, corporate financial reporting theory, economics, management accounting, physics and complexity. The study suggests that the conceptualisation of flow in general-purpose corporate financial reporting theory could contribute to rendering stable guidance for further coherent theoretical development, and improve on the alignment of the theory with the dynamics of the current global economy. This finding creates the opportunity to explore a variety of new reporting approaches from a scientific perspective, which could aid to enhance the disclosure of useful financial information.
\end{abstract}

Keywords: complexity, corporate financial reporting theory, energy, entropy, flow

\section{Introduction}

This study was inspired by the individual projects of the International Accounting Standards Board (IASB) and the US Financial Accounting Standards Board (FASB), commencing in 2001 with the objective of enhancing the usefulness of the then generally titled "income

1. Ms Antoinette Rehwinkel is a senior lecturer in the Department of Financial Accounting, University of South Africa (UNISA), Pretoria, South Africa. Email: Rehwia@unisa.ac.za

2. Professor Daniël G Gouws is a research professor in the Department of Financial Management, University of Pretoria (UP), Pretoria, South Africa. Email: Daan.Gouws@up.ac.za 
statement" by rethinking the interpretation of the concept "financial performance". Given that performance relates to the activities of a business entity, and that the conduct and outcome of business activities are represented by the disclosure of flows of discrete values in financial statements, the relationship between financial performance and the occurrence of flow was noted.

Concerning the abovementioned projects, the boards each developed a conceptual model for reporting on income and expenses and conducted preliminary testing. Neither of these models was approved as they were significantly different. During April 2004, in recognition of financial performance being too broad in scope to be presented by a single financial statement or earnings figure, the IASB and FASB enlarged their "income statement" projects by commencing a joint research project on financial statement presentation in its entirety. From this inclusive approach, it can be inferred that financial performance relates to all the corporate financial statements. Hereby flow disclosure from an integrated perspective is encouraged in that performance-related information is threaded throughout an entire set of corporate financial statements, vertically within each statement, and horizontally across the statements.

Apart from ascribing such a holistic scope to the interpretation of corporate financial performance, the problem remains that a clear description of the concept is not available and hence the disclosure thereof is compromised. With financial performance viewed as a pillar of corporate financial reporting theory, the Financial Reporting Faculty of the Institute of Chartered Accountants in England and Wales (ICAEW 2012:7) states:

\section{the IASB should review how company performance is reported as a priority. A definite view on what is meant by performance ... is long overdue. ... [U]ntil this issue is satisfactorily resolved, there will remain prima facie grounds for continued criticism of IFRS [International Financial Reporting Standards] reporting.}

Assuming that corporate financial reporting theory (hereafter also referred to as reporting theory) is developed with scientific rigour, it is questionable why the aforementioned research projects, at such a fundamental level, were undertaken at an advanced stage of theoretical development - given that the fundamentals in theory ought to be secured prior to specialisation. In view of the lack of such methodology, the development of reporting theory often leads to making adjustments at a fundamental level. This compromises a prime function of fundamental theory, namely to render stable orientation. Consider, for example, that the 2010 Conceptual Framework is explicitly viewed as secondary to the international accounting standards (South African Institute of Chartered Accountants (SAICA) 2010: Conceptual Framework - 3), while adherence to scientific development procedures should have resulted in this hierarchy of prominence being arranged the other way around.

Arguments in favour of developing theory according to the flow of energy are ample in the socio-scientific field, including that of corporate financial reporting (Csikszentmihalyi 2002; Gaffikin 2006:4; Rockefeller 2011; Clyde 2014). These arguments support the viewpoint that the flow of energy is fundamental to the disclosure of reality, since reality is all about continuous change, a concept "far more radical than we are at first inclined to suppose" (Bergson 1911:1).

This study addresses the research problem, the research objective and methodology, and then discusses i) observations of flow in reality; ii) the origin of and prerequisites for flow; iii) the socio-scientific application of flow; iv) the impact of the flow traits of the Fourth Economy on the dynamics of individual business entities; and v) the relativity of the value of time caused by changing flows of energy. In conclusion, an overview is given of the main envisaged 
contributions that the conceptualisation of flow in reporting theory could make to enhance the scientific standing and usefulness thereof.

\section{Research problem}

Corporate financial reporting theory lacks a stable and reality-related orientation as it does not have a simple, overarching and realistic basis on which to found i) the Conceptual Framework for Financial Reporting; ii) the Framework for the Preparation and Presentation of Financial Statements; and iii) International Accounting Standard (IAS) 1: Presentation of Financial Statements, as issued by the IASB. This compromises the scientific stature and usefulness of reporting theory.

To indicate the significance of this problem, consider the joint project undertaken during 2004 by the IASB and the FASB on financial statement presentation. One of the aims of the project was to address the disadvantages of the fragmented disclosure of financial information by suggesting the introduction of a principle of cohesiveness (FASB 2010:12). Since the IASB and the FASB view cohesive reports as disclosing information by "story lines", whereby the relationship between items across the financial statements is made clear, and the statements therefore complement one another (FASB 2010:10), this suggestion was actually a step towards reporting according to a theory of flow. However, the motivation given by the boards for introducing the principle, namely to increase the usefulness of corporate financial reports (hereafter also referred to as reports), was from a practical rather than a scientific perspective. Ideally, the development of reporting theory ought to be guided also from a scientifically and theoretically sound perspective. Sterling $(1967: 99,107)$ supports scientific guidance by arguing that a major problem in accounting is developing a basic information system because accounting change is driven from practice to theory, and that if accounting theory could be developed the other way around, it would be the most significant development since Pacioli ${ }^{3}$. Coetsee (2010:2) likewise states that a "crucial dilemma in accounting research is that there is currently no comprehensive theory of accounting on which accounting research can be based".

Complementary to a positional orientation, we posit that by introducing an underlying concept of flow, coherent development in reporting theory could be supported, both in terms of methodology and contents. This viewpoint agrees with that of Largay and Weaver (2009:37), who argue that the proposals of the International Financial Reporting Standards Foundation and the FASB can motivate the disaggregation of accounting and business performance data in order to arrive at improved integrated disclosure: for example, by measuring and disclosing assets at different points in time within various contexts (Barth 2013:[n.p.]).

From the perception that all in reality is in flow (Bergson 1911:363), positions do not exist. They are merely assumed points in time that are incorporated into observation schemes to ease

3. Fra Luca Pacioli, an Italian monk and lecturer in mathematics, authored a book on arithmetic in 1494 titled Summa de Arithmetica Geometria Proportioni et Proportionalita (All of Arithmetic, Geometry and Proportion). This book contains a section called De Computis et Scripturis (Of Reckonings and Writings), which includes Pacioli's description of the double-entry bookkeeping system as applied at the time. Pacioli wrote this section to standardise the recording procedures of business transactions, thereby formally introducing double-entry bookkeeping in the field of accounting practice (Green 1930:91). 
comprehension at the expense of rendering truthful representation. For example, Einstein introduced a cosmological constant to his general theory of relativity to yield a simplified unchanging model of the universe, which he later considered the biggest mistake of his scientific career (Bryson 2004:167). Likewise, Nicolis and Prigogine (1977:1) argue that:

Classical physics has emphasized stability and permanence. [But] we now see that, at best, such a qualification applies only to very limited aspects. Wherever we look, we discover evolutionary processes leading to diversification and increasing complexity.

Based on Bergson's philosophical reasoning, it is deduced that the two pillars of corporate financial reporting theory, namely financial performance and financial position, ought not to be equal in prominence because positions actually do not exist. In line with Bergson's reasoning, emphasis is currently frequently placed on the disclosure of financial performance rather than on position. For example, it is asserted that "a reporting entity's financial performance as represented by comprehensive income and its components is the most important information" (SAICA 2010: Conceptual Framework - 28). Similarly, Johnsson and Kihlstedt (2005:33) argue that it is the analysis of business performance that is of prime significance. Nonetheless, it is important to recognise that financial performance and position are indivisibly connected because the financial position of a business entity serves as a primary initial condition that drives financial performance, and in turn, the affected financial performance changes the entity's financial position.

The integrated disclosure of financial performance and position has the potential advantage that the ability and efficiency of self-regulation are more clearly disclosed, which could contribute to indicate the future sustainability of a business entity. Rockefeller (2011:564), in favour of considering integrated flow-structure relationships, argues against those flow theories that disregard stasis in its entirety. In view of the complementarity of financial performance and position, we posit that the prominence of financial performance is lacking because the disclosure of performance according to flow is limited, resulting in financial statements that claim or give the impression that flow is disclosed while only summative values are given. As such, summative values do not represent flow, neither does the difference between two values at the beginning and end of a financial year. What does reflect flow is, among others, the disclosure of a less discrete series of events or changes.

The disclosure of flow becomes more important when a throughput of energy is required to sustain a system. Isolated or closed systems conserve energy, but open systems such as business entities have to create and sustain energy throughput to survive. ${ }^{4}$ Therefore, if a system is open, different sustenance attributes come into play than those required for closed systems. Since business entities are open, these other attributes ought to be identified and reported on.

From a flow-based perspective, the annual or bi-annual disclosure of financial information is too discrete and therefore such information could ease the smoothing of volatile financial values, legitimately or otherwise, which in turn impedes truthful representation. Since smoothed information is repetitive, it is less useful because it adds limited information value. A decrease in the usefulness of smoothed or excessively discrete information is particularly notable in fast-changing, highly interactive environments, as financial information could lose

4. An isolated system is viewed as a system that does not exchange (typically) energy, matter and information with its environment, while an open system does (Jantsch 1980:32). A closed system is one that to a good approximation is cut off from its environment, in such a way that the system cannot interact with it (Lockwood 2007:189). 
its relevance substantially over very short time spans. Consider that during the period 1998 to 2003, no less than 100 of the Fortune 1000 companies lost at least 55 per cent of their market capital within approximately 30 days (Johnsson \& Kihlstedt 2005:145).

The positional disclosure of financial values in corporate financial statements is vested in the main source from where the data for the preparation of the statements is obtained, namely a trial balance at the end of a financial period. A trial balance discloses i) the balances of nominal accounts, these are summated financial values that have accumulated during a financial period under review - related to financial performance; and ii) the balances of existing asset, equity and liability accounts, being financial values at the end of a financial period that could have originated during financial periods prior to the period under review - related to financial position.

Since a trial balance is merely prepared at a specific date, it does not indicate the differing timeframes of reporting on financial performance and position. Hereby the presentation of the dynamics of business entities in financial statements is restricted to balances of accounts at single points in time. For example, the timeframes of reporting on nominal accounts differ and can be shorter than that of financial position accounts. The reason for this is that the balances of nominal accounts represent the result of the flow of financial values occurring within a single financial period, while the balances of financial position accounts could have originated from values that were accumulated over periods longer than the period under review.

The summated disclosure of values that have accumulated over too long a period of time, for example the sum of the sales or purchases of trading inventory for an entire year, impedes the accuracy of forecasts because the flow of the related transactions has been compressed into a single point in time, thereby largely removing the use of dynamics from forecasting procedures. Bollt and Sun (2014:1) emphasise the importance of disclosing the dynamics of complex systems such as economies according to information contents, flow and causality. Similarly, in the event of conceptualising flow in reporting theory at base level, the disclosure of the flow of financial values ought to be addressed in terms of type, contents and context. In all three of these cases, the effectiveness of reporting theory is limited. For example, in terms of type, the disclosure of the core dynamics of a business entity is inadequate because financial statements are not presented per core activities. In terms of contents, reporting theory allows the disparate disclosure of transactions and events in that the flow thereof is not required to be presented coherently in and across the financial statements. In terms of context, the authors concur with the viewpoint of SAICA (2010: Conceptual Framework - 29) that "a reporting entity cannot provide reasonably complete information about its financial performance ... without identifying and measuring its economic resources and the claims", since activities and the results thereof cannot be clearly understood when viewed in disaggregation, as is currently the case.

To provide flow-based information requires disclosure in line with the traits of the economic environments within which business entities function, as well as the different financial values that can be assigned to a given asset or liability - depending on the frames of reference applied by the presenters and the users of the information. Some of these flow-based requirements have - unintentionally - been met. For example, Discussion Paper DP/2014/1, concerning accounting for dynamic risk management, proposes the application of a portfolio revaluation 
approach (IFRS Foundation 2014: [n.p.]), but the motivation for the approach is not based on attempts to found reporting theory on flow.

The traditional research method of breaking an assumed stationary system into parts contributes to the fragmented representation of the dynamics of business entities. This methodology, in the view of Hawking and Mlodinow (2008:15), is completely wrong; they argue that if everything in the universe depends on everything else in a fundamental way, it might be impossible to get close to a full representation by independently investigating parts of the problem. Likewise, Rudolph and Valsiner (in Rudolph 2013:5) show that integrated wholes rather than disaggregated stimuli are experienced in reality, yet what is usually available to our analytic schemes are tools with which to break down the wholes into elementary constituents, resulting in losing precisely the qualities of the phenomena that are important to portray.

\section{Research objective and methodology}

The main aim of this study is to complement the research conducted by the IASB and the FASB on financial performance and financial statement presentation by investigating the potential of introducing an overarching principle, concept or theorem of flow to serve as a stable basis for the development of coherent general-purpose corporate financial reporting theory. In addition, the aim is to assess reporting theory in terms of the core dynamics and traits of the global economy and of the business entities successfully functioning in it.

Given the fundamentality of the research problem, the research methodology applied in this study is conducting an introductory theoretical transdisciplinary investigation to arrive at a conclusion concerning the application of a flow-based founding principle, concept or theorem by which to guide theoretical development. The relevance of applying hypothetical-deductivist reasoning at this level of research is supported by, among others, Gaffikin (1988:18, 32; 2006:7) and Cincotti, Sornette, Treleaven, Battiston, Caldarelli, Hommes and Kirman (2012:366).

The main fields of investigation are corporate financial reporting theory, philosophy, economics, management accounting, complexity and physics. Philosophy was selected as a starting point from a broad, conceptual and flow-based perspective. In early Greek philosophy, for example, the original motion of the universe was viewed as that

\section{out of which all things arose. Motion is thus given the primary place in the order of existence; it is the originating activity, and all other things have their source or genesis in this motion (Wartofsky 1968:427).}

The study fields of economics and management accounting were selected because they are related to corporate financial reporting, in that economists and management accountants use general-purpose corporate financial reports in fulfilling various facets of their responsibilities. In order for corporate financial reports to be useful within this context, they need to adequately supply the information required by these stakeholders, including information on the dynamics - the performance - of business entities.

To enhance the usefulness of an existing framework often requires the consideration of other perspectives concerning sustainable systems that apply similar frameworks. The application of the theories of complexity is a method of achieving such an aim, as these theories collectively form a transdisciplinary study field viewed by complex systems researchers as essential for progress on the most important scientific problems concerning the dynamics of the complex systems of our day (Mitchell 2009:300). Since economies are viewed as complex systems, comprising among others trading business entities, one finds that economists attempt to 
explain market behaviour in terms similar to those used in the description of complex systems: for example, dynamic patterns in global behaviour and the processing of signals and information (Mitchell 2009:9-10).

The application of certain basic concepts of physics, being a natural science in contrast with the social sciences, is motivated briefly below.

- Physics "can be said to be the most fundamental and general of all the sciences" (Kragh 2002:447) and, similar to the research objective of this study, such fundamentality is sought by physicists seeking basic principles, ideas and mathematical formulations on which all further understanding can be based (Kadanoff 1993:401, 403).

- There is a growing natural-social alliance in science. For example, Einstein (in Calaprice 2005:234) notes that scientific research is based on the assumption that all events, including the actions of mankind, are determined by the laws of nature. Wheatley (1999:8) likewise infers that "intentionally or not, we work from a world view that is strongly anchored in the natural sciences", and Goldratt (1990:27) states that the phenomena witnessed daily in any organisation are part of nature, waiting for a science to be developed.

- Physics includes studies on the motion of energy, which also forms part of the objective of this study.

- Since information is viewed as a physical property (Gleick 2012:355), the concept of "information" is addressed in fundamental physics (Brenner 2014:396), and currently there is a growing tendency in physics to study information (Zurek 1990:vii). Similarly, in Chapter 1 (OB2) of the 2010 Conceptual Framework for Financial Reporting, the disclosure of useful financial information to existing and potential investors, lenders and other creditors in making decisions about providing resources to the entity, is stated as the objective of general-purpose corporate financial reporting (SAICA 2010:[n.p.]).

- As reporting theory addresses the disclosure of financial position and performance, so physics, by analogy, is similarly "concerned with the properties of matter [stocks/position] and energy [flows/performance] and the relationships between them" (Dardo 2004:488).

- Prigogine and Stengers (1984:xv) argue that attempts to understand open social systems in pure classical terms are doomed to failure. Progressing from the classical viewpoint of certainty, theories in physics introduced concepts such as complementarity and indeterminability (uncertainty) in measurement. These concepts are also evident in principle-based reporting theory.

- As theoretical physics advances, integrated theories arise such as string theory, which aims to merge two extreme theories in physics, namely general relativity, by which things that are huge and heavy are studied, with quantum mechanics, by which things that are small and light are studied (Greene 2003:3-4). By similarly using a cohesive corporate financial reporting principle such as flow, reporting theory could likewise advance towards integrated theoretical concepts.

- The consideration of empirically based laws, theories and principles could enhance the scientific standing of general-purpose corporate financial reporting theory. 


\section{Flow}

\subsection{The relevance of flow in reality}

Examples of energy flowing through and within natural and social systems, and of attempts to comprehend such flow, abound - mainly since the sustenance of various systems is dependent on the throughput and transformation of energy. Time as an artefact was created specifically to orientate human perception according to flow. Einstein (in Martin \& Ott 2013:8) deduces: "I feel myself so much a part of everything living that I am not in the least concerned with the beginning or ending of the concrete existence of any one person in this eternal flow." From a philosophical perspective, Bergson (1911:196) reasons that matter "looked at as an undivided whole, must be a flux rather than a thing" and therefore he reconciled the inert (stationary/position) with the living (flow). In the field of physics, Bohm (1980:ix, xi) observes that the nature of reality forms

\section{a coherent whole, which is never static or complete, but ... an unending process of movement and unfoldment ... science itself is demanding a new, non-fragmentary world view, in the sense that the present approach of analysis of the world into independently existent parts does not work very well in modern physics.}

From a socio-natural viewpoint, Emoto (2005:xvi) argues that "moving, changing, flowing ... is what life is all about". From the perspective of reporting, Hubbard (1998:90) asserts that nobody likes the succession of points since they are jarring, and that physicists prefer images constructed by the disclosure of continuous transformations, so that these images correspond to something that they can grasp.

\subsection{The origin of and prerequisites for flow}

\subsubsection{Origin of flow}

In attempts to grasp the flow of energy, studies from differing perspectives on the origin of flow were conducted. From the stance of astronomy and physics, when Hubble in 1929 found proof that the universe is expanding, it was deduced that the universe and therefore the flow of its energy had a beginning, typically referred to as the "big bang" (Hawking 1989:9-10). This reference is important since it indicates that time has a starting point and measures the duration or experience of change. Accordingly, to suggest a theoretical departure point for the conceptualisation of flow in reporting theory, we assert that the flow of the financial energy of a business entity commences at the time of the incorporation of the entity.

\subsubsection{Prerequisites for flow}

For the flow of energy to occur, we posit that at least three basic constituents are required, namely useful energy, disequilibrium (imbalance) and networks.

\subsubsection{Useful energy}

Any active system, whether natural or social, has energy in various forms. Without an inventory of free and useful energy, no flow of energy can occur within or through a system. In the case of an open, dynamic system such as a business entity, the flow of energy is caused by the application of intellectual and other energies such as assets, to achieve a financial goal within an economic environment. 
In the field of social dynamics, conceptualising reporting theory according to the flow of "useful energy" could be considered as too intangible. This was also the case during the development of physics, when energy was initially viewed as being too abstract to be introduced into an empirically based science. At the time, reference was made to matter rather than to the energy within the matter. It took almost a century from Newton's death in 1727 to arrive at the scientific acceptance of the term "energy" in the natural sciences, when in 1807 Young (in Atkins 2003:84) stated that this term could be applied with great propriety. Once recognised, it was argued that energy, and not matter, is the essence of reality, and that mechanics ought to fall under the general laws of energetics (Kragh 2002:7-10). By acknowledging energy as a universal natural phenomenon, Atkins (2003:97) describes it as the "currency of cosmic accountancy". Brenner (2014:396) similarly assigns such fundamentality to energy by stating that although the relationship between energy and information is inseparable, energy is more fundamental than information because information emerges from it. Based on the viewpoints of Atkins and Brenner, financial statements ought to account for the dynamics of corporaterelated energies, complementary to financial positions.

\subsubsection{Disequilibrium in the distribution of energy}

Without an imbalance in the distribution of useful energy within a system and/or between a system and its environment, the flow of energy cannot occur. When the distribution of energy within a natural system is sufficiently uneven, the system is typically described as being in disequilibrium. From this perspective, a sufficient measure of disequilibrium is viewed as an essential trait to ensure the sustenance of a system because it causes flow, and flow is related to life.

Two laws in physics that explain the flow of energy because of such disequilibrium are the first and second laws of thermodynamics, combined referred to as the law of entropy. The first law states that the total energy of a thermodynamic system, assumed to be isolated, is conserved (Penrose 2005:690) because an isolated system cannot absorb or transfer energy from or to its environment. Accordingly, the law of entropy states that the total amount of energy in an isolated thermodynamic system is constant because it cannot be destroyed or created. In elementary terms, the second law states that in an isolated thermodynamic system, heat flows from hotter to colder particles until, most likely, an equal temperature, on average, in the system is reached (Penrose 2005:689). The law of entropy, asserting that a thermodynamic system is isolated, states that this equalisation process is irreversible, hence the forward-pointing arrow associated with time.

The measure of converted energy within an isolated thermodynamic system is called entropy, and the conversion process of the useful energy is called entropy production. The higher the entropy of such a system, the lesser its entropy production rate, and the closer to thermal equilibrium, a stationary-like form of existence, the energy of the system is. Once the energy distribution of an isolated thermodynamic system reaches equilibrium, small deviations from such equilibrium may occur, but not significant ones.

Contrary to an isolated system, an open system can absorb or transmit energy from or to its environment, deeming the conversion process of energy and the outcome thereof reversible and less predictable. Since the first and second laws of thermodynamics apply only to isolated thermodynamic systems, the rote application thereof to represent the dynamics of open systems 
would be incorrect. In the case of business entities this would be more specifically so since they are driven to financially enrich stakeholders, while isolated thermodynamic systems simply act according to the law of entropy, with no gain as aim.

To disclose and analyse the energy distribution of a wide range of non-thermodynamic open systems, derivatives of the law of entropy were developed by means of statistical mechanics (Kapur \& Kesavan 1992:1; Gribbin 2005:122-23; Mitchell 2009:48, 49 \& 52). Similar to isolated systems, the conversion of energy by open systems is referred to as entropy production. The decrease of entropy produced by open systems is referred to as negative entropy (negentropy in short) production. Open systems either dissipate or adjust when the energy distribution thereof is in or close to equilibrium over too long a period. In such cases, equilibrium points serve as transformation points, indicating imminent change for the better or the worse.

Negentropy production is sustained by the networks of a system that allow for the flow of energy through the system. Hence, the core financial in- and outflows via the networks of a business entity determine its entropy or negentropy production. By analysing these flows, the sustainability of business entities and consequently the risk of investing in them, can be estimated.

In terms of corporate financial reporting, it is important to note the difference between Newtonian and entropic equilibrium. Book entries made according to the double-entry principle, whereby a cause equals an effect, result in the disclosure of information congruent with "balanced" Newtonian equilibrium. This reporting method ensures mathematical accuracy to a degree, but does not focus on the disclosure of continuance, thereby comprising the truthful representation of flow. On the other hand, because profiteering business entities are averse to arriving at entropic equilibrium, entropy or entropy production rate disclosures contribute to forecasting sustainability. Reporting according to Newtonian equilibrium is thus position-like, whereas reporting on the aversion of entropic equilibrium is flow-oriented, deeming these two forms of reporting complementary.

In the fields of economics and commerce, McCauley (2004:xi) argues that there is no empirical evidence for the existence of any form of economic equilibrium - of Adam Smith's so-called stabilising Invisible Hand. Ball (2012:34) is in agreement:

Traditional economic theory makes several fundamental assumptions that seem now to be excessively simplistic. The first is to imagine that the economy is an equilibrium system. ... This assumption stems from the origins of microeconomic theory as an analogue of theories of equilibrium physical systems such as gases, which have stable, unchanging states. The physical sciences have long since moved on to describe non-equilibrium processes ... but economics has not. The implications are huge. The 'equilibrium paradigm' explains why the so-called dynamic stochastic general equilibrium models prevalent in economic forecasting ignore the potential for major fluctuations such as slumps or crashes.

Arthur (2013:3) emphasises that a theory of equilibrium must be bypassed regarding anything in an economy that changes. Therefore, Arthur (2013:1) shows that over the last 25 years a new form of economics, named complexity economics, has emerged. This form has a complementary framework to that of classical economics, in that classical economics is based on equilibrium while complexity economics is based on attributes pertaining to disequilibrium, including strategies and actions, the relativity of time and changing structures. Farmer, Gallegati, Hommes, Kirman, Ormerod, Cincotti, Sanchez and Helbing (2012:309) state that 
an equilibrium-efficient market paradigm cannot aid the explanation of phase transitions, since it prohibits the studying of dynamics within different timescales and neglects assessing friction, without which it is difficult to understand entropy and other path-dependent effects. Cincotti et al (2012:366), convinced of the necessity of maintaining a measure of disequilibrium in the distribution of energy in economic systems in order for them to survive, propose the introduction of the phenomenon of disequilibrium - to allow for flow - as a theoretical default.

Rudolph and Valsiner (in Rudolph 2013:1-2) state that images of stability are created and presented as being perpetual, and that this is probably the greatest fiction produced. In line with this viewpoint, we argue that corporate financial reporting theory, rooted in classical Newtonian equilibrium theorems, requires new models by which to portray current business dynamics. The development of such models will require re-addressing the theory, starting at fundamental level, by reconsidering for instance the accounting assumption of "going concern", given the continuous attraction of business entities to dissolution, according to the law of entropy.

To represent and analyse entropic fluctuation, a fluctuation theorem applicable to diverse systems in disequilibrium has been developed (Dewar 2003:632). This theorem acknowledges that the most effective dynamics of open systems occur at levels where energy throughputs are far from equilibrium - in other words high in volatility (Nicolis \& Prigogine 1977:24). Therefore, the fluctuation theorem merits investigation into the possibility that financial values, such as earnings, have been artificially smoothed when the values are inexplicably similar in trend over a too extended period in time, or when the values lack correlation with the dynamics of the economic environment within which is functioned over too many periods in time.

\subsubsection{Networks}

Since open systems require effective networks by which to transfer energy (for example, energy vested in assets or information), network studies is a prominent research topic in the field of analysing complex systems (Mitchell 2006:1196) such as cities, social networks and economies.

Due to the diversity of complex systems, no universally accepted definitions of the terms "complexity" and "complex systems" exist. Similar to the term "flow", these concepts are described in context, relative to an area under review. A crude description of a complex system entails that $i$ ) the dynamics of the components of the system are relatively simple - compared to those of the entire system (Gribbin 2005:136); ii) the system is decentralised and selforganising because the components thereof spontaneously interrelate to function as an organised whole; iii) the system displays emergent behaviour because the interactions of the components thereof "lead to coherent collective phenomena, ... [where] the whole is more than the sum of its components" (Coveney \& Highfield 1996:7); and iv) the system achieves goals by developing a great number of pathways (Prigogine, Nicolis \& Babloyantz 1972:24). The more complex a system, the more integrated it is, and the more energy throughput it requires to sustain itself (Rifkin 1980:244-45). The emphasis placed on the dynamics of complex systems indicates that complexity theories are mainly concerned with the representation of the flow of energies by means of networks, and that the disclosure of business interaction by means of networks could improve the truthful representation of business dynamics. 
While social scientists had already developed network theories by the middle of the 20th century, it is the sophisticated globalised networks that emphasise the importance of network theories (Lima 2011:11). One finds for example that there

\section{is a central difference between the old and the new economies: the old industrial economy was driven by economies of scale: the new information economy is driven by the economies of networks (Shapiro E' Varian 1998:173).}

Network theories that are currently emerging, such as complexity theories, differ from earlier developed network theories such as graph theory, in that greater emphasis is placed on the cohesive disclosure of the dynamics of systems by incorporating network theory at a fundamental level in related reporting frameworks, so that the understanding of the nature of these systems can be improved (Newman, Barabási \& Watts 2006:4).

Assessed against complexity, the proposed principle of cohesive financial statement presentation (FASB 2010:12) is viewed as a step in the right direction if one is endeavouring to conceptualise flow in corporate financial reporting theory. Viewed holistically, complexity theories pertain not only to the single facet of financial statement presentation, but to the entire financial reporting spectrum of observing, measuring, recording, presenting and analysing the dynamics of business entities within the context of the traits of the economic environments within which the entities operate.

\subsection{The socio-scientific application and interpretation of flow}

\subsubsection{Socio-scientific application}

The incorporation of flow in the socio-scientific scene commenced centuries ago. For instance, in 1629 Hobbes aspired to develop a theory of social governance for which he needed a fundamental axiom about human behaviour, rooted in the deepest soil of science. By observing the continuity of motion around him, he became convinced that the law of inertia, in that it confirms that all in existence, including people, is in constant flow, was the axiom that he was seeking (Ball 2005:14-17).

Similarly, Emmeche (1994:18) infers that "Life is a process, and it is the form of this process, not the matter, that is the essence of life. One can therefore ignore the material, and instead abstract from it the logic that governs the process, taking it out of the concrete material form of the life we know", and Goertzel (in Robertson \& Combs 1995:135, 136) suggests that the mind and brain are networks of interacting processes, governed by a law of motion.

Rockefeller (2011:557) observes that flow is one of the most crucial aspects of a new socioscientific perspective in terms of scale, agency, locality and mobility on the global scene, especially when related to the networks of systems. Rockefeller's observation agrees with findings in the fields of economic and business management, where Prechter (1996:11) refers to a wave principle, which he views as the most valuable tool ever developed for interpreting market actions and forecasting future events.

In the field of business management, Nonaka, Toyama and Hirata (2008:xix) suggest that managers focus on the processes by which a firm and its environment evolve, since all things flow in continuous interaction and in relation to each other, and that this applies to human beings, firms and the larger environment. They argue that all firms face the contradictory requirement of having to be both stable and flexible to survive, and that firms overcome this 
contradiction by managing flow. Likewise, Zhang (2009:355) argues in favour of industrial business entities forming complex transportation networks to optimise product flows.

Zak and Waddell ${ }^{5}$ (2011:51,56) indicate that flow-driven management is at the heart of excellent manufacturing, since all the really big leaps in manufacturing have been big improvements on flow, and that high flow in manufacturing means low cost. Ohno (1988:128), founder of the Toyota Production System, advises that the first aspect to consider in the creation of a manufacturing system is putting the correct flow of energy into the process. Ohno (1988:129-130) describes work flow as the value added to a product while the product flows along; he identifies seven categories of production waste produced by a manufacturing system, namely overproduction, waiting, the transportation of goods, over-processing, stationary inventories, the excessive moving of personnel and the manufacturing of defective parts and products. All these categories constrain the flow of energy in some way. Womack and Jones $(2003: 7,15,24)$ assert that breakthroughs come from addressing entire value streams rather than from disconnected processes, and therefore they include the flow of energy as one of the five principles of lean theory - a theory asserting that value creation is optimised when activities are arranged in such sequence that interruption is limited to achieve more with less. Goldratt's (1990:ix, 7, 9) theory of constraints has a similar aim, namely to remove all the main constraints deterring the achievement of an entity's goals by implementing a ceaseless process of ongoing improvement.

Since the quality of the flow of energy relates to the frequency of events (Broken Symmetry 2009b), such frequency ought to be represented in financial statements. Waddell (in Broken Symmetry 2009a) argues that because frequency averages for each account are not disclosed in financial statements, we have blinded ourselves by excluding information about flow, and as a result accountants can manipulate information without leaving a trace.

\subsubsection{Interpretation within context}

The significance of the term "flow" lies in its multiplicity, although this complicates efforts to render a single description thereof (Rockefeller 2011:557). Therefore, it is necessary to interpret "flow" within a specific context.

To comprehend flow first requires recognising its dualistic nature. Linguistically the term "flow" can be used as a verb, for example water that flows, or as a noun, when it is viewed as an act of flowing or movement. One could relate such dualism to the interdependent relationship between financial performance and position.

In physical terms, it suffices to note that the term "flow" emerged from employing a fluid perspective in the literal sense, showing flow to "move steadily and continuously" (Paperback Oxford English Dictionary 2006:288). From a psychological perspective, Csikszentmihalyi (2002:xi) developed a theory of flow in which it is viewed as a person being totally involved with life. Such an optimised state of being is "characterised by high concentration and a sense

5. Waddell has spent over 30 years in virtually all facets of manufacturing, including accounting, industrial engineering, supply chain production and quality management. He has consulted hundreds of companies in a wide variety of industries, including multibillion-dollar global organisations (Zak \& Waddell 2011:xii). 
of control, which are facilitators of performance" (Eklund in Engeser 2012:78). In that Csikszentmihalyi's theory distinctly relates flow to performance, the initiative is supported to research flow in reporting theory with specific reference to financial performance. The relationship between mutual fund flows and past financial performance was researched by Ferreira, Keswani, Miguel and Ramos (2012:1759) to determine how the economic, financial and mutual fund industries impact on the sensitivity of the relationship. Their findings show that the flow-performance relationship is influenced by the degree of economic development of a country, pointing to reporting in congruence with the dynamics of economic markets when reporting according to flow.

Within the scope of this study, flow is viewed as any movement or transformation of financial energy types, such as materials or cash, through and within a business entity. Hence the focus is placed on i) financial performance as it relates to the core activities - the areas of high concentration and control - of a business entity, ii) financial performance-position relationships, and iii) the environment within which entities function.

\subsection{Flow traits of the Fourth Economy}

Brenner (2014:393) argues that it is impossible to address the disclosure of any information without first considering the properties of the environment in which the informational phenomena unfold. This requirement points to the necessity of aligning the traits of relevant economic environments and business dynamics with reporting theory.

Table 1: Distinctive attributes of the Third and Fourth Economies

\begin{tabular}{|c|c|c|}
\hline & Third Economy & Fourth Economy \\
\hline Period & mainly 19 th century & mainly 21 st century \\
\hline Technology & $\begin{array}{l}\text { industrial, focusing on physical processes such as } \\
\text { the use of machinery and the flow of financial } \\
\text { capital }\end{array}$ & $\begin{array}{l}\text { post-industrial, focusing on } \\
\text { mind-based processes such as } \\
\text { the development and application } \\
\text { of intellectual capital, and on } \\
\text { information technology }\end{array}$ \\
\hline Market changes & slow and predictable & fast and unpredictable \\
\hline Production & predetermined and mass production & flexible and lean \\
\hline Networks & local and simple & $\begin{array}{l}\text { global and complex, viewed as } \\
\text { interdependent, effective } \\
\text { relationships stands key to } \\
\text { survival }\end{array}$ \\
\hline Competitive edge & size: the big eats the small & speed: the fast eats the slow \\
\hline Competitive alliance & isolated & merged \\
\hline Key scarce resource & financial capital & intellectual capital and time \\
\hline Operational focus & supplier-driven & customer-driven \\
\hline $\begin{array}{l}\text { Main financial performance } \\
\text { indicators }\end{array}$ & financial corporate reports & market capitalisation \\
\hline Management & bureaucratic, centralised & decentralised \\
\hline Time & focus on absolute time and the past & focus on relative and real time \\
\hline
\end{tabular}


Source: Compiled by the authors, based on research conducted by Johnsson and Kihlstedt (2005)

Johnsson and Kihlstedt $(2005: 15,42,86)$ refer to the current global economy as the Fourth Economy and explain that it adds an additional layer of prominent dynamics to that of the Third, industrial-driven economy (see Table 1, which shows the distinctive attributes of the Third and Fourth Economies). The flows of economic-related energies usually increase in speed as an economy progresses from one level to the next, emphasising the importance of flow disclosure by entities functioning in the Fourth Economy.

Concerning the Fourth Economy, emphasis is placed on intellectual processes, speed, uncertainty, networks, holism, customer focus, decentralisation and real time. The creation of networks is viewed as so significant by Johnsson and Kihlstedt $(2005: 46,82)$ that they infer that interaction, and not tangible assets, is the catalyst of growth in the Fourth Economy and that:

It would be amazing, indeed, if a reporting system developed in the days of Columbus and Copernicus were still adequate in our times. ... [W]e have presented abundant examples to show that the reliability of accounting is severely limited. The characteristics of the fourth economy cut deep into the relevance of accounting.

Similar observations caused accounting standard-setters to rethink the direction that financial reporting ought to take in the fourth economic era (Nehmer 2011:73).

Table 2 shows that the attributes of the Fourth Economy relate more to the characteristics of evolving than to those of structure-preserving systems.

Table 2: Characteristics of structure-preserving and evolving systems

\begin{tabular}{|c|c|c|c|}
\hline Characteristic & \multicolumn{2}{|c|}{ Structure-preserving systems } & Evolving systems \\
\hline Total system dynamics & static (no dynamics) & $\begin{array}{l}\text { conservative self- } \\
\text { organization }\end{array}$ & $\begin{array}{l}\text { dissipative self- } \\
\text { organization (evolution) }\end{array}$ \\
\hline Structure & $\begin{array}{l}\text { equilibrium structure, } \\
\text { permanent }\end{array}$ & $\begin{array}{l}\text { devolution toward } \\
\text { equilibrium structure }\end{array}$ & $\begin{array}{l}\text { dissipative structure (far } \\
\text { from equilibrium) } \\
\text { evolving }\end{array}$ \\
\hline Function & no function or allopoiesis & $\begin{array}{l}\text { reference to equilibrium } \\
\text { state }\end{array}$ & $\begin{array}{l}\text { autopoiesis (self- } \\
\text { reference) }\end{array}$ \\
\hline Logical organization & $\begin{array}{l}\text { statistical oscillations in } \\
\text { reversible processes }\end{array}$ & $\begin{array}{l}\text { irreversible processes in } \\
\text { direction of equilibrium } \\
\text { state }\end{array}$ & $\begin{array}{l}\text { cyclical (hypercycle), } \\
\text { irreversible sense of cycle } \\
\text { rotation }\end{array}$ \\
\hline Internal state & equilibrium & near equilibrium & non-equilibrium \\
\hline $\begin{array}{l}\text { Relationship with } \\
\text { environment }\end{array}$ & \multicolumn{2}{|c|}{ isolated or open (growth possible) } & $\begin{array}{l}\text { open (continuous } \\
\text { balanced exchange) }\end{array}$ \\
\hline
\end{tabular}

Source: Jantsch (1980:34)

It is therefore asserted that reporting theory ought to relate to the characteristics of evolving systems, requiring the introduction of reporting elements such as networking, self-reference ability, entropy and the cycles of flow. 
The Fourth Economy is characterised by the compression of time (Gleick 2000:6-7, 9) causing the value of time to increase when more events occur within absolute time spans such as a solar calendar year. Consider for instance that the growth rate of knowledge, a main compressor of time, doubled over 1500 years (from A.D. 1 to A.D. 1500), and has consecutively doubled again over 300, 100, 20, 7 and 2 years. The estimation is that by 2020 our collective body of knowledge will double within 72 days (Biech 2007:4). The value of labour also increases under the compression of time, leading to compromised measurement when disclosed in absolute temporal terms.

\subsection{The impact of flow on the relativity of time}

Bergson (1911:362) argues that reality ought to be represented according to changes that occur over time; he suggests that

we should no longer be asking where a moving body will be, what shape a system will take, through what state a change will pass at a given moment: the moments of time, which are only arrests of our attention, would no longer exist; it is the flow of time ... that we should be trying to follow.

In science the measurement of the flow of energy is done mainly from the perspective of absolute or relative time. In physics, the relativity of time is validated by Einstein's special theory of relativity, showing that the flow of time through space is not constant; that it varies according to a spatial frame of reference since space and time merge into a unified variable called space-time. He explained:

In order to be able to describe at all that which fills up space and is dependent on the coordinates, space-time ... must be thought of at once as existing, for otherwise the description of 'that which fills up space' would have no meaning" (Einstein 2014:156).

Upon the realisation of the impact that different timeframes have on the outcome of observations, the powerful mechanistic paradigm of absolutism in science started to crumble, leading Prigogine (1980:xvi) to conclude that time is not a boundary, fixed in periods, but an operator within systems. For the sake of simplicity, scientists often base their theories on absolute rather than relative time. For example, Newton (in Capra 1983:51) narrowed down his classical laws of motion by assuming that time is absolute. He hypothesised: "Absolute, true, and mechanical time ... of itself and by its own nature, flows uniformly, without regard to anything external". The impracticality of such an assertion is clear when studying the dynamics of interconnected, open systems.

Currently, the relativity of time is recognised from various perspectives (Callender 2011:1). For example, Prigogine (1980:xvii) shows that any person studying time cannot avoid taking into account the cultural and social changes that impact on it. Ijsseling (1992:409-410) concludes that "all human relationships change, not the least important of which is the relationship to time and space ... In this new era, almost all fundamental notions from traditional philosophy receive a different meaning. ... Time and space in particular, ... change fundamentally", and Bell (1999:42) states that the changing nature of knowledge and technology has a direct influence on the pace of change, and that the real effect thereof is visible in the tightening of social networks. In the Fourth Economy the value of time is influenced by the volatility and increase of economic activities. Since substantial volatility is often associated with high investment risk, the disclosure of volatile financial values is often veiled by value smoothing 
and the application of absolute time units. Taleb (2007:xliii) warns that faked stability is misleading. Similarly, Tweedie $(2008: 116,119)$ notes that

volatility is not invented and when companies report volatility that volatility is real. The change in the value of assets and liabilities is an economic event and all businesses are exposed to economic volatility.

Therefore, what ought to be investigated by users of financial reports are any unexplained deviations of the dynamics of a business entity from the dynamics of the market within which it functions. The disclosure of corporate financial information according to relative time is done by means of fair value or inflationary reporting, among other methods. For practical reasons, and to aid the comparability of financial statements, the application of relative time remains restricted since the length of a financial year is viewed as an absolute unit of time, namely 12 solar calendar months - independent of the value of time as influenced by the flow of financially related energies through business entities. To unify financial performance and related changing financial structures within a relative temporal framework would be challenging, but considering the notable contribution made to the development of theoretical physics by introducing a unified concept of space-time, it is envisaged that the introduction of relative time to reporting theory could similarly enhance the usefulness of reports prepared accordingly.

\section{Conclusion}

In discipline after discipline, stasis is losing the battle to movement, process and contingency (Phipps 2012:26), with the pursuit of the mystery of motion being regarded as one of the greatest stories of civilisation (Mazur 2007:9). We are in agreement, and suggest that the introduction of a flow perspective to corporate financial reporting theory could improve the compliance thereof to the basic requirements of theory-setting in science. According to Habermas (1984:39) these include rightness, appropriateness and comprehensibility. Based on these aspects, we assert that the conceptualisation of flow in reporting theory could enhance the scientific standing of the theory and improve the usefulness of financial reports prepared accordingly in a number of fundamental ways, such as:

- rendering a stable and relevant orientation for coherent theoretical development founded on the overarching concept of flow;

- introducing universal theories of systemic dynamics to corporate financial reporting theory;

- disclosing activity-based information that shows the quantitative and qualitative flow of transactions and events;

- aligning corporate financial reporting theory to the dynamics of sustainable business entities and the Fourth Economy;

- cohesively disclosing financial information;

- restricting the manipulation of financial information;

- enhancing the transparency of corporate financial reports; and

- disclosing large volumes of financial data by means of patterns to ease understanding (Haken 1988:5; Card, Mackinlay \& Shneiderman 1999:6). New reporting methodologies that could represent large amounts of data in a more statistical and comprehensive way ought to be explored. 
In overview, the conceptualisation and disclosure of flow from a transdisciplinary perspective in the field of corporate financial reporting theory merits further investigation. If we pursue this challenge, a revolutionary journey in the development of reporting theory could be awaiting us. As Wheeler states:

(T)here must be, at the bottom of it all, not an equation, but an utterly simple idea. And ... that idea, when we finally discover it, will be so compelling, so inevitable, that we will say to one another, 'Oh, how beautiful. How could it have been otherwise?'

(Wheeler in Gaither \& Cavazos-Gaither 2012:1008)

\section{References}

ARTHUR, W.B. 2013. Complexity Economics: A Different Framework for Economic Thought. Santa Fe Institute Working Paper: 2013-04-012, pp. 1-22.

ATKINS, P. 2003. Galileo's Finger: The Ten Great Ideas of Science. Oxford: Oxford University Press.

BALL, P. 2005. Critical Mass: How One Thing Leads to Another. London: Arrow Books.

BALL, P. 2012. Why Society is a Complex Matter: Meeting Twenty-first Century Challenges with a New Kind of Science. Heidelberg: Springer.

BARTH, M.E. 2013. Measurement in Financial Reporting: The Need for Concepts. Accounting Horizons, online preprint. Available from: <http://aaajournals.org/toc/acch/0/0> [Accessed: 3 June 2014].

BERGSON, H. 1911. Creative Evolution. London: Macmillan.

BELL, D. 1999. The Coming of Post-Industrial Society: A Venture in Social Forecasting. New York, NY: Basic Books.

BIECH, E. 2007. Thriving Through Change: A Leader's Practical Guide to Change Mastery. Alexandria, VA: ASTD Press.

BOHM, D. 1980. Wholeness and the Implicate Order. London and New York: Ark Paperbacks, Routledge.

BOLLT, E.M. \& SUN, J. 2014. Editorial Comment on the Special Issue of "Information in Dynamical Systems and Complex Systems". Entropy.

Available from: <http://aajournals.org/toc/acch/0/0> [Accessed: 18 July 2014].

BRENNER, J.E. 2014. The Logic of the Physics of Information. Information, No. 5, pp. 389-403. Available from: <www.mdpi.com/2078-2489/5/3/389 [Accessed: 10 July 2014].

BROKEN SYMMETRY. 2009a. Goldratt, Lean, Flow, and Financial Statements. Available from: http://brokensymmetry.typepad.com/broken_symmetry/2009/07/goldratt-lean-flowand-financial-statements.html> [Accessed: 16 April 2012].

BROKEN SYMMETRY. 2009b. Why Accounting Information Should Be Reported in Real Time. Available from: 
http://brokensymmetry.typepad.com/broken_symmetry/2009/03/why-accountinginformation-should-be-reported-in-real-time.html [Accessed: 16 April 2012].

BRYSON, B. 2004. A Short History of Nearly Everything. London: Black Swan.

CALAPRICE, A. 2005. The New Quotable Einstein. Princeton, NJ: Princeton University Press.

CALLENDER, C. ed. 2011. The Oxford Handbook of Philosophy of Time. New York, NY: Oxford University Press.

CAPRA, F. 1983. The Turning Point. London: Flamingo.

CARD, S.K., MACKINLAY, J.D. \& SHNEIDERMAN, B. 1999. Readings in Information Visualisation: Using Vision to Think. San Diego, CA: Academic Press.

CINCOTTI, S., SORNETTE, D., TRELEAVEN, P., BATTISTON, S., CALDARELLI, G., HOMMES, C. \& KIRMAN, A. 2012. An economic and financial exploratory. The European Physical Journal Special Topics, Vol. 214, pp. 361400.

CLYDE, P. 2014. Information Flow Analysis and the Theory of the Firm. John Wiley \& Sons; Wiley Online Library.

COETSEE, D. 2010. The Role of Accounting Theory in the Development of Accounting Principles. Meditari Accountancy Research, Vol. 18, No. 1, pp. 1-16.

COVENEY, P. \& HIGHFIELD, R. 1996. Frontiers of Complexity: The Search for Order in a Chaotic World. London: Faber \& Faber.

CSIKSZENTMIHALYI, M. 2002. Flow: The Classic Work on How to Achieve Happiness. London: Rider.

DARDO, M. 2004. Nobel Laureates and Twentieth-Century Physics. Cambridge: Cambridge University Press.

DEWAR, R. 2003. Information theory explanation of the fluctuation theorem, maximum entropy production and self-organized criticality in non-equilibrium stationary states. Journal of Physics A: Mathematical and General, Vol. 36, No. 3, pp. 631-641.

EINSTEIN, A. 2014. Relativity. New York, NY: Routledge Great Minds.

EMMECHE, C. 1994. The Garden in the Machine: The Emerging Science of Artificial Life. Princeton, NJ: Princeton University Press.

EMOTO, M. 2005. The Hidden Messages in Water. London: Beyond Words Publishing.

ENGESER, S. ed. 2012. Advances in Flow Research. New York, NY: Springer.

FARMER, J.D., GALLEGATI, M., HOMMES, C., KIRMAN, A., ORMEROD, P., CINCOTTI, S., SANCHEZ, A. \& HELBING, D. 2012. A complex systems approach to constructing better models for managing financial markets and the economy. The European Physical Journal Special Topics, Vol. 214, pp. 295-324.

FERREIRA, M.A., KESWANI, A., MIGUEL, A.F., \& RAMOS, S.B. 2012. The flowperformance relationship around the world. Journal of Banking E Finance. 
Available from: <http://www.cass.city.ac.uk/_data/assets/pdf_file/0015/125610/Flowperformance-relationship-around-the-world.pdf> [Accessed: 14 November 2013].

FINANCIAL ACCOUNTING STANDARDS BOARD (FASB). 2010. FASB Staff Draft of an Exposure Draft on Financial Statement Presentation. Connecticut, Financial Accounting Standards Board of the Financial Accounting Foundation. Available from: <http://www.fasb.org> [Accessed: 1 August 2010].

GAFFIKIN, M.J.R. 1988. Legacy of the Golden Age: Recent Developments in the Methodology of Accounting. ABACUS, Vol. 24, No. 1, pp. 16-36.

GAFFIKIN, M. 2006. The Critique of Accounting Theory. School of Accounting and Finance. University of Wollongong, Working Paper 25.

GAITHER, C.C. \& CAVAZOS-GAITHER, A.E. eds. 2012. Gaither's Dictionary of Scientific Quotations. 2nd ed. New York, NY: Springer.

GLEICK, J. 2000. Faster: The Acceleration of Just About Everything. London: Abacus.

GLEICK, J. 2012. The Information. London: Fourth Estate.

GOLDRATT, E.M. 1990. What is this thing called THEORY OF CONSTRAINTS and how should it be implemented? New York, NY: North River Press.

GREENE, B.R. 2003. The Elegant Universe: Superstrings, Hidden Dimensions, and the Quest for the Ultimate Theory. New York, NY: W.W. Norton \& Company.

GREEN, W.L. 1930. History and Survey of Accountancy. Brooklyn, New York: Standard Text Press.

GRIBBIN, J. 2005. Deep Simplicity: Chaos, Complexity and the Emergence of Life. London: Penguin Books.

HABERMAS, J. 1984. The Theory of Communicative Action: Reason and the Rationalization of Society, Vol. 1, translated by T. McCarthy. Boston, MA: Beacon Press.

HAKEN, H. 1988. Information and Self-organization: A Macroscopic Approach to Complex Systems. Berlin: Springer-Verlag.

HAWKING, S.W. 1989. A Brief History of Time: From the Big Bang to Black Holes. London: Bantam Books.

HAWKING, S.W. \& MLODINOW, L. 2008. A Briefer History of Time. London: Bantam Press.

HUBBARD, B.B. 1998. The World According to Wavelets: The Story of a Mathematical Technique in the Making. 2nd ed. Wellesley, MA: AK Peters.

INSTITUTE OF CHARTERED ACCOUNTANTS IN ENGLAND AND WALES (ICAEW): FINANCIAL REPORTING FACULTY. 2012. The future of IFRS: Information for better markets initiative. London: ICAEW.

INTERNATIONAL FINANCIAL REPORTING STANDARDS (IFRS)

FOUNDATION. 2014. Discussion Paper: Accounting for Dynamic Risk

Management: a Portfolio Revaluation Approach to Macro Hedging. International Accounting Standards Board (LASB), DP/2014/1. 
IJSSELING, S. 1992. Time and Space in Technological Society. Man and World, Vol. 25, Nos. 3-4, pp. 409-419.

JANTSCH, E. 1980. The Self-Organising Universe: Scientific and Human Implications of the Emerging Paradigm of Evolution. Oxford and New York: Pergamon Press.

JOHNSSON, H.V.A. \& KIHLSTEDT, P.E. 2005. Performance-Based Reporting: New Management Tools for Unpredictable Times. Princeton, NJ: John Wiley.

KADANOFF, L.P. 1993. From Order to Chaos: Essays: Critical, Chaotic and Otherwise. Singapore: World Scientific.

KAPUR, J.N. \& KESAVAN, H.K. 1992. Entropy Optimization Principles with Applications. New York, NY: Academic Press.

KRAGH, H. 2002. Quantum Generations: A History of Physics in the Twentieth Century. Princeton, NJ: Princeton University Press.

LARGAY III, J.A. \& WEAVER, S.C. 2009. The Proposed Financial Reporting Overhaul and Business Valuation. Management Accounting Quarterly, Vol. 10, No. 2, pp. 24-37.

LIMA, M. 2011. Visual Complexity: Mapping Patterns of Information. New York, NY: Princeton Architectural Press.

LOCKWOOD, M. 2007. The Labyrinth of Time, Introducing the Universe. Oxford: Oxford University Press.

MARTIN, W. \& OTT, M. 2013. The Cosmic View of Albert Einstein. New York, NY: Sterling Publishing.

MAZUR, J. 2007. The Motion Paradox: The 2,500-Year-Old-Puzzle Behind all the Mysteries of Time and Space. New York, NY: Dutton.

McCAULEY, J.L. 2004. Dynamics of Markets: Econophysics and Finance. Cambridge: Cambridge University Press.

MITCHELL, M. 2006. Complex systems: Network thinking. Artificial Intelligence, Vol. 170, No. 18, pp. 1194-1212.

MITCHELL, M. 2009. Complexity: A Guided Tour. New York, NY: Oxford University Press.

NEHMER, R.A. 2011. Information Entropy, Economic Analysis and Financial Reporting. Review of Business Information Systems, Vol. 5, No. 3, pp. 73-79.

NEWMAN, M., BARABÁSI, A. \&WATTS, D.J. 2006. The Structure and Dynamics of Networks. Princeton, NJ: Princeton University Press.

NICOLIS, G. \& PRIGOGINE, I. 1977. Self-Organization in Nonequilibrium Systems: From Dissipative Structures to Order through Fluctuations. New York, NY: John Wiley.

NONAKA, I., TOYAMA, R. \& HIRATA, T. 2008. Managing Flow: A Process Theory of the Knowledge-Based Firm. Hampshire, UK: Palgrave Macmillan.

OHNO, T. 1988. Toyota Production System: Beyond Large-Scale Production. Portland, OR: Productivity Press. 
PAPERBACK OXFORD ENGLISH DICTIONARY. 2006. 6th ed. Edited by Soanes, C. with Hawker, S. and Elliot, J. Oxford: Oxford University Press.

PENROSE, R. 2005. The Road to Reality: A Complete Guide to the Laws of the Universe. New York, NY: Alfred A. Knopf.

PHIPPS, C. 2012. Evolutionaries: Unlocking the Spiritual and Cultural Potential of Science's Greatest Idea. New York, NY: HarperCollins.

PRECHTER, R.R., Jr. 1996. At the Crest of the Tidal Wave: A Forecast for the Great Bear Market. Gainesville, GA: New Classics Library.

PRIGOGINE, I. 1980. From Being to Becoming: Time and Complexity in the Physical Sciences. San Francisco, CA: W.H. Freeman.

PRIGOGINE, I., NICOLIS, G. \& BABLOYANTZ, A. 1972. Thermodynamics of Evolution. Physics Today, Vol. 25, No. 11, pp. 23-28.

PRIGOGINE, I. \& STENGERS, I. 1984. Order out of Chaos: Man's New Dialogue with Nature. Toronto: Bantam Books.

RIFKIN, J. 1980. Entropy: A New World View. New York, NY: The Viking Press.

ROBERTSON, R. \& COMBS, A. eds. 1995. Chaos Theory in Psychology and the Life Sciences. Mahwah, NJ: Lawrence Erlbaum Associates.

ROCKEFELLER, S.A. 2011. "Flow”. Current Anthropology, Vol. 52, No. 4, pp. 557-578.

RUDOLPH, L. ed. 2013. Qualitative Mathematics for the Social Sciences: Mathematical models for research on cultural dynamics. New York, NY: Routledge.

SHAPIRO, C. \& VARIAN, H.R. 1998. Information Rules: A Strategic Guide to the Network Economy. Boston, MA: Harvard Business School Press.

SOUTH AFRICAN INSTITUTE OF CHARTERED ACCOUNTANTS (SAICA). 2010. SAICA Handbook 2010/2011, Volume 3: Accounting, Ethics and Circulars (including translations). South Africa: LexisNexis.

STERLING, R.R. 1967. A Statement of Basic Accounting Theory: A Review Article. Journal of Accounting Research, Vol. 5, No. 1 (Spring, 1967), pp. 95-112.

TALEB, N.N. 2007. Fooled by Randomness: The Hidden Role of Chance in Life and in the Markets. 2nd ed. London: Penguin Books.

TWEEDIE, D. 2008. Bringing transparency to financial reporting: towards an improved accounting framework in the aftermath of the credit crisis. Banque de France. Financial Stability Review, No. 12, pp. 115-120.

WARTOFSKY, M.W. 1968. Conceptual Foundations of Scientific Thought: An Introduction to the Philosophy of Science. New York, NY: Macmillan.

WHEATLEY, M.J. 1999. Leadership and the New Science: Discovering Order in a Chaotic World. 2nd ed. San Francisco, CA: Berrett-Koehler.

WOMACK, J.P. \& JONES, D.T. 2003. Lean Thinking: Banish waste and create wealth in your corporation. New York, NY: Free Press.

ZAK, A. \& WADDELL, B. 2011. Simple Excellence: Organizing and Aligning the Management Team in a Lean Transformation. New York, NY: CRC Press. 
ZHANG, J. 2009. Energy flows in complex ecological systems: A review. Journal of Systems Science and Complexity, Vol. 22, pp. 345-359.

ZUREK, W.H. ed. 1990. Complexity, entropy and the physics of information. Proceedings Volume VIII, Santa Fé Institute, CA: Addison-Wesley. 